OPEN ACCESS

Edited by:

Masakazu Toi,

Kyoto University, Japan

Reviewed by:

Marcus Vetter,

University Hospital of Basel,

Switzerland

Praveen Vikas,

University of lowa Hospitals and

Clinics, United States

*Correspondence:

Binghe $X u$

xubinghe@medmail.com.cn

Specialty section:

This article was submitted to

Breast Cancer,

a section of the journal

Frontiers in Oncology

Received: 22 February 2021

Accepted: 20 April 2021

Published: 11 May 2021

Citation:

Lin S, Mo H, Li Y, Guan X, Chen Y,

Wang $Z$, Yuan $P$, Wang J, Luo $Y$,

Fan $Y$, Cai R, Li Q, Chen S, Zhang P,

Li Q, Ma F and Xu B (2021)

Risk Factors and Survival of

Patients With Liver Metastases

at Initial Metastatic Breast Cancer

Diagnosis in Han Population.

Front. Oncol. 11:670723.

doi: 10.3389/fonc. 2021.670723

\section{Risk Factors and Survival of Patients With Liver Metastases at Initial Metastatic Breast Cancer Diagnosis in Han Population}

\author{
Shaoyan Lin ${ }^{1}$, Hongnan Mo ${ }^{1}$, Yiqun $L^{1}{ }^{1}$, Xiuwen Guan ${ }^{1}$, Yimeng Chen ${ }^{1}$, Zijing Wang ${ }^{1}$, \\ Peng Yuan ${ }^{2}$, Jiayu Wang ${ }^{1}$, Yang Luo ${ }^{1}$, Ying Fan ${ }^{1}$, Ruigang Cai ${ }^{1}$, Qiao $L^{1}{ }^{1}$, Shanshan Chen ${ }^{1}$, \\ Pin Zhang ${ }^{1}$, Qing $\mathrm{Li}^{1}$, Fei $\mathrm{Ma}^{1}$ and Binghe $\mathrm{Xu}^{1 *}$ \\ 1 Department of Medical Oncology, National Cancer Center/National Clinical Research Center for Cancer/Cancer Hospital, \\ Chinese Academy of Medical Sciences \& Peking Union Medical College, Beijing, China, ${ }^{2}$ Department of VIP Medical \\ Services, National Cancer Center/National Clinical Research Center for Cancer/Cancer Hospital, Chinese Academy of \\ Medical Sciences \& Peking Union Medical College, Beijing, China
}

The risk factors for morbidity and mortality in patients with breast cancer liver metastases (BCLM) upon initial metastatic breast cancer (MBC) diagnosis have not been adequately identified in Han population. Data of 3,161 female patients who were initially diagnosed with MBC from December 1991 to September 2019 and treated in the China National Cancer Center were extracted and a total of 2,263 MBC patients were included in our study, among which 550 patients had liver metastases. Multivariable logistic regression was performed to identify risk factors for the presence of liver metastases at initial MBC diagnosis. Univariable and multivariable Cox proportional hazards regression analyses were conducted to determine prognostic factors for the survival of BCLM patients. Patients with hormone receptor (HR)-negative, human epidermal growth factor receptor 2 (HER2)-positive (35.0\% of the entire population) subtype had the highest incidence of liver metastases. De novo stage IV breast cancer, HR-/HER2+ and HR+/HER2+ subtypes were associated with higher odds of liver metastases and patients with lung metastases had lower risk of liver metastases at initial MBC diagnosis. The median overall survival of BCLM patients was 31.4 months and BCLM patients with HR+/HER2subtype had the longest survival of 38.2 months. Older age, worse performance status, later stage of initial breast cancer, triple-negative subtype and lung metastases were significantly associated with a poorer prognosis in BCLM patients. Our study offers insights into the incidence and prognosis of BCLM patients at initial MBC diagnosis in Han population.

Keywords: metastatic breast cancer, incidence, risk factors, liver metastases, survival 


\section{INTRODUCTION}

Breast cancer is the most common cancer and the leading cause of cancer death in female worldwide (1). It is reported that $~ 6 \%$ of breast cancer patients present with de novo metastatic disease and $\sim 30 \%$ of patients with early-stage breast cancer will eventually recur (2). With a median survival time of $\sim 3$ years, metastatic breast cancer (MBC) remains incurable (3).

Liver metastasis is one of the most frequent distant metastases of breast cancer (4), with an incidence of $~ 30 \%(5,6)$ in MBC patients. Earlier studies have reported that the outcome of patients with breast cancer liver metastases (BCLM) is usually poor, and the median survival is $12-20$ months (7-9). The tumor subtypes are demonstrated to be associated with the prognosis of BCLM patients and triple-negative breast cancer (TNBC) confers the shortest survival when compared with other subtypes (10). Additionally, growing evidence implies that the distinct molecular subtypes show preferential sites of recurrence (4, 11). Breast cancer patients with human epidermal growth factor receptor 2 (HER2) overexpression are more likely to develop liver metastases compared with HER2-negative patients (12). However, the risk factors and survival in patients with BCLM upon initial MBC diagnosis in Han population remain poorly identified.

In this study, we aimed to investigate the risk factors for morbidity and mortality of liver metastases in newly diagnosed MBC patients in Han population. We also characterized clinicopathological features and overall survival (OS) of BCLM patients according to breast cancer subtype.

\section{MATERIALS AND METHODS}

\section{Patients}

We retrospectively extracted data of 3,161 female patients who were initially diagnosed with MBC from December 1991 to September 2019 and treated in the China National Cancer Center. Patients with unknown hormone receptor (HR) or HER2 status $(\mathrm{n}=579)$, unknown metastatic sites $(\mathrm{n}=65)$ and follow-up less than 1 month from initial MBC diagnosis ( $\mathrm{n}=$ 254) were excluded, leaving 2,263 patients in the final cohort eligible for incidence analysis. Among these, 550 patients had liver metastases when first diagnosed with MBC. All included participants were followed until June 30, 2019 or date of deaths by telephone contacts or outpatient visits.

\section{Study Variables}

We collected the following clinical data of included patients from medical records in hospital information system: age at MBC diagnosis, Eastern Cooperative Oncology Group (ECOG)

\footnotetext{
Abbreviations: AJCC, American Joint Committee on Cancer; BCLM, breast cancer liver metastases; CI, confidence interval; ECOG, Eastern Cooperative Oncology Group; FISH, fluorescent in-situ hybridization; HER2, human epidermal growth factor receptor 2; HR, hormone receptor; IHC, immunohistochemistry; MBCm metastatic breast cancer; OR, Odds ratio; OS, overall survival; TNBC, triple-negative breast cancer.
}

score, initial stage of breast cancer, tumor subtype, site of metastases and survival month. HR status was measured by routine immunohistochemistry (IHC) and cancers with $1-100 \%$ estrogen receptor IHC staining or 1-100\% progesterone receptor IHC staining were considered HR-positive. HER2 IHC3+ or amplified fluorescent in situ hybridization (FISH) were reported HER2-poxitive. Patients were divided into four different subtypes: HR+/HER2-, HR-/HER2+, HR+/HER2+ and triplenegative (HR-/HER2-). Breast cancer staging was according to the 8th American Joint Committee on Cancer (AJCC) TNM staging system.

\section{Statistical Analysis}

Categorical data was described using numbers and percentages and the chi-square test was performed to compare category variables among different breast cancer subtypes in BCLM patients. Incidence of liver metastases upon initially $\mathrm{MBC}$ diagnosis was calculated among the entire cohort stratified by breast cancer subtype. Multivariable logistic regression was used to determine whether age, ECOG, initial stage of breast cancer, tumor subtype, and site of extrahematic metastases were associated with the presence of liver metastases at first MBC diagnosis. Odds ratios (ORs) with $95 \%$ confidence intervals (CIs) were calculated. OS was defined as the time from the initial MBC diagnosis to death. We utilized Kaplan-Meier analysis and logrank test to estimate the cumulative OS within subsets of breast cancer subtypes and compare the differences. Univariable and multivariable Cox proportional hazards regression analyses were conducted to identify the independent prognostic factors significantly influencing the OS of BCLM patients. Statistical analyses were performed independently by Shaoyan Lin, MD, using SPSS statistical software version 23. A two-sided $P$ value $<0.05$ was considered as statistically significant.

\section{RESULTS}

\section{Patient Characteristics}

Of the 2,263 included patients, 24.3\% (550) developed liver metastases when first diagnosed with $\mathrm{MBC}$. Of patients with BCLM, 20.4\% (112) presented with de novo stage IV disease. Table 1 summarized the clinicopathological features of BCLM patients according to breast cancer subtype. HR+/HER2-, HR-/ HER2+, HR+/HER2+ and triple-negative subtypes comprised $46.0 \%$ (253), $19.1 \%$ (105), $22.4 \%$ (123) and $12.5 \%$ (69) of BCLM patients, respectively. Compared with other groups, HR+/HER2patients with BCLM were less likely to present with de novo MBC $(P=0.000)$. Besides, HR $+(\mathrm{HR}+/ \mathrm{HER} 2-$ and HR $+/ \mathrm{HER} 2+)$ patients with BCLM had a higher rate of bone metastases than HR- (HR-/HER2+ and triple-negative) patients $(P=0.020)$.

\section{Incidence}

Table 2 listed the result of incidence of liver metastases according to breast cancer subtype among the entire cohort. Of the 2,263 patients presenting with $\mathrm{MBC}, 52.1,13.3,16.1$ and $18.5 \%$ had HR+/HER2-, HR-/HER2+, HR+/HER2+ and triplenegative subtypes, respectively. Patients with HR-/HER2+ 
TABLE 1 | Clinicopathological features of patients with liver metastases at initial metastatic breast cancer diagnosis stratified by breast cancer subtype.

\begin{tabular}{|c|c|c|c|c|c|}
\hline Characteristic & HR+/HER2-, N (\%) & HR-/HER2+, N (\%) & HR+/HER2+, N (\%) & Triple-negative, N (\%) & $P$ value \\
\hline All patients & $253(46.0)$ & $105(19.1)$ & $123(22.4)$ & $69(12.5)$ & \\
\hline Age & & & & & 0.887 \\
\hline$<50$ & $125(49.4)$ & $51(48.6)$ & $65(52.8)$ & $33(47.8)$ & \\
\hline$\geq 50$ & $128(50.6)$ & $54(51.4)$ & $58(47.2)$ & $36(52.2)$ & \\
\hline ECOG & & & & & 0.444 \\
\hline 0 & $66(26.1)$ & $25(23.8)$ & $27(22.0)$ & $17(24.6)$ & \\
\hline 1 & $178(70.4)$ & $75(71.4)$ & $90(73.2)$ & $45(65.2)$ & \\
\hline 2 & $9(3.6)$ & $5(4.8)$ & $6(4.9)$ & 7 (10.1) & \\
\hline T-stage & & & & & 0.094 \\
\hline T1 & $65(25.7)$ & $22(21.0)$ & $32(26.0)$ & $13(18.8)$ & \\
\hline $\mathrm{T} 2$ & $119(47.0)$ & $41(39.0)$ & $52(42.3)$ & $27(39.1)$ & \\
\hline T3 & $15(5.9)$ & $15(14.3)$ & $7(5.7)$ & $11(15.9)$ & \\
\hline $\mathrm{T} 4$ & $15(5.9)$ & $10(9.5)$ & $6(4.9)$ & $4(5.8)$ & \\
\hline Unknown & $39(15.4)$ & $17(16.2)$ & $26(21.1)$ & $14(20.3)$ & \\
\hline N-stage & & & & & 0.063 \\
\hline NO & $64(25.3)$ & $26(24.8)$ & $21(17.1)$ & $18(26.1)$ & \\
\hline N1 & $67(26.5)$ & $31(29.5)$ & $23(18.7)$ & $11(15.9)$ & \\
\hline N2 & $52(20.6)$ & $19(18.1)$ & 35 (28.5) & $14(20.3)$ & \\
\hline N3 & $45(17.8)$ & $23(21.9)$ & 29 (23.6) & $13(18.8)$ & \\
\hline Unknown & $25(9.9)$ & $6(5.7)$ & $15(12.2)$ & $13(18.8)$ & \\
\hline M-stage & & & & & 0.000 \\
\hline MO & $229(90.5)$ & 77 (73.3) & $82(66.7)$ & $50(72.5)$ & \\
\hline M1 & $24(9.5)$ & $28(26.7)$ & 41 (33.3) & $19(27.5)$ & \\
\hline Lung metastases & & & & & 0.733 \\
\hline No & $175(69.2)$ & $74(70.5)$ & 81 (65.9) & $44(63.8)$ & \\
\hline Yes & $78(30.8)$ & $31(29.5)$ & $42(34.1)$ & 25 (36.2) & \\
\hline Brain metastases & & & & & 0.353 \\
\hline No & $246(97.2)$ & 98 (93.3) & 118 (95.9) & $67(97.1)$ & \\
\hline Yes & $7(2.8)$ & $7(6.7)$ & $5(4.1)$ & $2(2.9)$ & \\
\hline Bone metastases & & & & & 0.020 \\
\hline No & $148(58.5)$ & $76(72.4)$ & 75 (61.0) & $51(73.9)$ & \\
\hline Yes & 105 (41.5) & $29(27.6)$ & $48(39.0)$ & $18(26.1)$ & \\
\hline
\end{tabular}

HR, hormone receptor; HER2, human epidermal growth factor receptor 2; ECOG, Eastern Cooperative Oncology Group.

TABLE 2 | Incidence of patients with liver metastases at initial metastatic breast cancer diagnosis according to breast cancer subtype.

\begin{tabular}{lccc}
\hline & $\begin{array}{c}\text { All metastatic } \\
\text { patients, N (\%) }\end{array}$ & $\begin{array}{c}\text { With liver } \\
\text { metastases }\end{array}$ & $\begin{array}{c}\text { Incidence of liver } \\
\text { metastases, \% }\end{array}$ \\
\hline HR+/HER2- & $1180(52.1)$ & 253 & 21.4 \\
HR-/HER2+ & $300(13.3)$ & 105 & 35.0 \\
HR+/HER2+ & $365(16.1)$ & 123 & 33.7 \\
Triple-negative & $418(18.5)$ & 69 & 16.5 \\
All subtypes & $2263(100.0)$ & 550 & 24.3 \\
\hline
\end{tabular}

HR, hormone receptor; HER2, human epidermal growth factor receptor 2.

(35.0\%) and HR+/HER2+ (33.7\%) subtypes shared the highest incidence proportions of liver metastases, while triple-negative (16.5\%) the lowest.

The multivariate logistic regression for the presence of liver metastases among the entire MBC population was displayed in Table 3. Patients with de novo stage IV breast cancer were more likely to present with liver metastases than recurrent MBC patients (M1 vs. M0, OR = 1.44, 95\% CI = 1.08-1.93, $P=0.013$ ). HR-/HER2+ (vs. HR+/HER2-, OR $=1.92,95 \% \mathrm{CI}=1.44-2.55, P=0.000)$ and $\mathrm{HR}+/ \mathrm{HER} 2+$ ( vs. HR+/HER2-, $\mathrm{OR}=1.80,95 \% \mathrm{CI}=1.38-2.34, P=$ 0.000 ) subtypes were associated with remarkably higher odds of liver metastases, while triple-negative subtype ( $v s$. HR+/HER2-, OR = $0.71,95 \% \mathrm{CI}=0.53-0.96, P=0.024$ ) was associated with significantly lower odds of liver metastases at first MBC diagnosis. Patients with lung metastases ( $v s$. without lung metastases, $\mathrm{OR}=0.78,95 \% \mathrm{CI}=$ $0.63-0.96, P=0.022$ ) had lower risk of liver metastases at diagnosis. Age, ECOG, T-stage, N-stage, brain and bone metastases showed no correlations with the presence of liver metastases at diagnosis.

\section{Survival}

With a median follow-up of 61.6 months, the median OS of the overall MBC population was 45.4 months. Figure 1 indicated that BCLM patients (median OS, 31.4 months) had significantly poorer prognosis than non-BCLM patients (median OS, 50.0 months, $P=$ 0.000 ) at first MBC diagnosis. The OS of BCLM patients stratified by breast cancer subtype was showed in Figure 2. BCLM patients with HR+/HER2 - subtype had the longest survival (38.2 months) while triple-negative the shortest $(18.0$ months, $P=0.000)$. The median OS of BCLM patients with HR-/HER2+ (vs. HR+/HER2-, $P=$ $0.282)$ and HR+/HER2+ (vs. HR+/HER2-, $P=0.518)$ subtypes were 29.0 and 31.9 months, respectively.

Univariable and multivariable Cox proportional hazards regression analyses were performed to assess the prognostic factors of BCLM patients (Table 4). The variables of age, ECOG, T-stage, Nstage, subtype, lung and bone metastases with $P<0.05$ in univariable analysis were incorporated into the multivariable regression analysis. Age $\geq 50$ years $(v s .<50$ years, $\mathrm{HR}=1.27,95 \% \mathrm{CI}=1.02-1.58$, 
TABLE 3 | Multivariate logistic regression for the presence of liver metastases at initial metastatic breast cancer diagnosis.

\begin{tabular}{|c|c|c|}
\hline Characteristic & OR (95\% Cl) & $P$ value \\
\hline \multicolumn{3}{|l|}{ Age } \\
\hline$<50$ & Reference & \\
\hline$\geq 50$ & $1.04(0.85,1.26)$ & 0.729 \\
\hline \multicolumn{3}{|l|}{ ECOG } \\
\hline 0 & Reference & \\
\hline 1 & $1.00(0.79,1.26)$ & 0.979 \\
\hline 2 & $1.52(0.91,2.54)$ & 0.110 \\
\hline \multicolumn{3}{|l|}{ T-stage } \\
\hline T1 & Reference & \\
\hline T2 & $1.03(0.80,1.32)$ & 0.834 \\
\hline T3 & $1.21(0.80,1.83)$ & 0.359 \\
\hline $\mathrm{T} 4$ & $1.09(0.66,1.78)$ & 0.738 \\
\hline Unknown & $0.71(0.51,1.00)$ & 0.047 \\
\hline \multicolumn{3}{|l|}{ N-stage } \\
\hline NO & Reference & \\
\hline N1 & $1.09(0.82,1.44)$ & 0.567 \\
\hline N2 & 1.35 (0.99, 1.83) & 0.055 \\
\hline N3 & $0.98(0.71,1.35)$ & 0.896 \\
\hline Unknown & $1.34(0.88,2.04)$ & 0.168 \\
\hline \multicolumn{3}{|l|}{ M-stage } \\
\hline $\mathrm{MO}$ & Reference & \\
\hline M1 & $1.44(1.08,1.93)$ & 0.013 \\
\hline \multicolumn{3}{|l|}{ Subtype } \\
\hline HR+/HER2- & Reference & \\
\hline HR-/HER2+ & $1.92(1.44,2.55)$ & 0.000 \\
\hline HR+/HER2+ & $1.80(1.38,2.34)$ & 0.000 \\
\hline Triple-negative & $0.71(0.53,0.96)$ & 0.024 \\
\hline \multicolumn{3}{|l|}{ Lung metastases } \\
\hline No & Reference & \\
\hline Yes & $0.78(0.63,0.96)$ & 0.022 \\
\hline \multicolumn{3}{|l|}{ Brain metastases } \\
\hline No & Reference & \\
\hline Yes & $0.75(0.45,1.26)$ & 0.276 \\
\hline \multicolumn{3}{|l|}{ Bone metastases } \\
\hline No & Reference & \\
\hline Yes & $0.85(0.69,1.05)$ & 0.142 \\
\hline
\end{tabular}

OR, odds ratio; Cl, confidence interval; ECOG, Eastern Cooperative Oncology Group; HR, hormone receptor; HER2, human epidermal growth factor receptor 2.

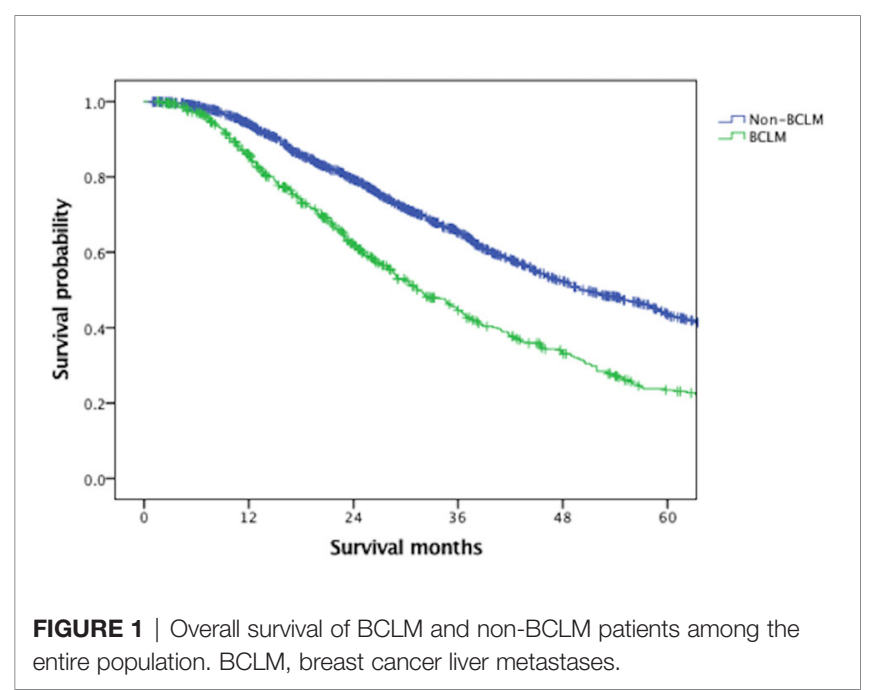

$P=0.031$ ), ECOG 1 (vs. ECOG 0, HR $=1.37,95 \% \mathrm{CI}=1.03-1.83$,

$P=0.032$ ), ECOG 2 (vs. ECOG 0, $\mathrm{HR}=1.93,95 \% \mathrm{CI}=1.17-3.18$,

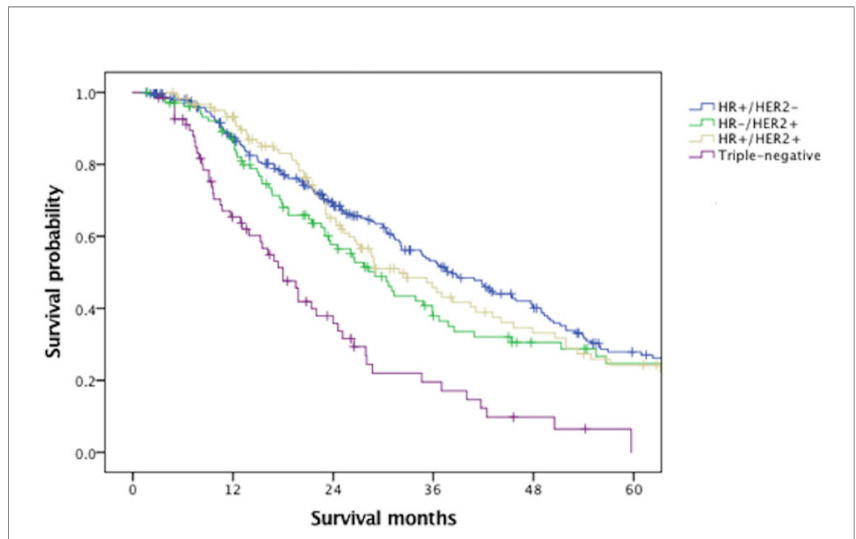

FIGURE 2 | Overall survival of patients with liver metastases stratified by breast cancer subtype. HR, hormone receptor; HER2, human epidermal growth factor receptor 2 .

$P=0.010), \mathrm{T} 4$ ( vs. T1, $\mathrm{HR}=1.62,95 \% \mathrm{CI}=1.02-2.58, P=0.043), \mathrm{N} 2$ (vs. N0, HR $=1.75,95 \% \mathrm{CI}=1.23-2.48, P=0.002$ ), N3 (vs. N0, HR = $1.50,95 \% \mathrm{CI}=1.05-2.14, P=0.025)$, triple-negative subtype ( $v s$. HR+/HER2 - , HR $=2.51,95 \% \mathrm{CI}=1.77-3.56, P=0.000)$ and lung metastases ( $v s$. without lung metastases, $\mathrm{HR}=1.60,95 \% \mathrm{CI}=1.27-$ 2.03, $P=0.000$ ) were significantly associated with an increased mortality.

\section{DISCUSSION}

In this article, we described the incidence, outcome and their associated risk factors of BCLM patients in newly diagnosed MBC patients in Han population. We identified 550 cases of liver metastases from initially diagnosed MBC patients, accounting for $24.3 \%$ of the entire cohort. Consistently, previous studies $(10,13)$ reported that $25.0-29.6 \%$ of the advanced breast cancer patients had the initial recurrence in liver. Table 1 indicated that compared with other subsets, HR+/HER2- patients with BCLM were more likely to present with recurrent disease, rather than de novo $\mathrm{MBC}(P=0.000)$, which were not found in the whole $\mathrm{MBC}$ population in earlier studies $(14,15)$. Besides, HR-positive patients with BCLM had a higher rate of bone metastases than HRnegative patients $(P=0.020)$, similar to previous studies $(4,16)$.

In accordance with other work $(9,12,17-19)$, our study demonstrated that patients with HER2-positive had the highest incidence of liver metastases (Table 2). A retrospective study including 3,276 patients with BCLM in the USA also indicated that patients with HR-/HER2+ (46.5\%) and HR+/HER2+ (37.5\%) subtypes had a propensity for liver metastases compared with HER2-negative subtypes (9). Some studies tried to figure out the molecular mechanisms associated with specific metastatic sites in breast cancer. Pierobon and colleagues found that increased incidence of PIK3CA mutations and activation of PI3K-AKTmTOR signaling axis, related to HER2 activation, were involved in liver metastases in breast cancer (20). Li et al. reported that HER2 enhanced the expression of CXCR4, a chemokine receptor, thus mediating the breast tumor metastasis to specific organs (21). 
TABLE 4 | Univariable and multivariable cox regression analyses of overall survival in BCLM patients.

\begin{tabular}{|c|c|c|c|c|c|}
\hline \multicolumn{3}{|c|}{ Univariable analysis } & \multicolumn{3}{|c|}{ Multivariable analysis } \\
\hline Characteristic & Hazard ratio $(95 \% \mathrm{Cl})$ & $P$ value & Characteristic & Hazard ratio $(95 \% \mathrm{Cl})$ & $P$ value \\
\hline Age & & & Age & & \\
\hline$<50$ & Reference & & $<50$ & Reference & \\
\hline$\geq 50$ & $1.25(1.01,1.54)$ & 0.040 & $\geq 50$ & $1.27(1.02,1.58)$ & 0.031 \\
\hline ECOG & & & ECOG & & \\
\hline 0 & Reference & & 0 & Reference & \\
\hline 1 & $1.45(1.09,1.92)$ & 0.010 & 1 & $1.37(1.03,1.83)$ & 0.032 \\
\hline 2 & $2.75(1.72,4.39)$ & 0.000 & 2 & $1.93(1.17,3.18)$ & 0.010 \\
\hline T-stage & & & T-stage & & \\
\hline T1 & Reference & & $\mathrm{T} 1$ & Reference & \\
\hline $\mathrm{T} 2$ & $1.10(0.84,1.45)$ & 0.470 & $\mathrm{~T} 2$ & $1.01(0.77,1.34)$ & 0.928 \\
\hline T3 & $1.80(1.20,2.70)$ & 0.005 & T3 & $1.11(0.71,1.74)$ & 0.658 \\
\hline $\mathrm{T} 4$ & $2.24(1.46,3.45)$ & 0.000 & $\mathrm{~T} 4$ & $1.62(1.02,2.58)$ & 0.043 \\
\hline Unknown & $1.02(0.73,1.44)$ & 0.892 & Unknown & $0.93(0.63,1.38)$ & 0.719 \\
\hline $\mathrm{N}$-stage & & & $\mathrm{N}$-stage & & \\
\hline NO & Reference & & NO & Reference & \\
\hline N1 & $1.16(0.84,1.61)$ & 0.363 & N1 & $1.13(0.82,1.57)$ & 0.457 \\
\hline N2 & $1.92(1.39,2.66)$ & 0.000 & N2 & $1.75(1.23,2.48)$ & 0.002 \\
\hline N3 & $1.71(1.22,2.38)$ & 0.002 & N3 & $1.50(1.05,2.14)$ & 0.025 \\
\hline Unknown & $1.43(0.96,2.13)$ & 0.079 & Unknown & $1.11(0.69,1.76)$ & 0.673 \\
\hline \multicolumn{6}{|l|}{ M-stage } \\
\hline $\mathrm{MO}$ & Reference & & & & \\
\hline M1 & $1.17(0.90,1.53)$ & 0.232 & & & \\
\hline Subtype & & & Subtype & & \\
\hline $\mathrm{HR}+/ \mathrm{HER} 2-$ & Reference & & $\mathrm{HR}+/ \mathrm{HER} 2-$ & Reference & \\
\hline HR-/HER2+ & $1.18(0.88,1.57)$ & 0.271 & HR-/HER2+ & $1.23(0.91,1.66)$ & 0.181 \\
\hline $\mathrm{HR}+/ \mathrm{HER} 2+$ & $1.08(0.82,1.43)$ & 0.576 & HR+/HER2+ & $1.05(0.79,1.39)$ & 0.755 \\
\hline Triple-negative & $2.73(1.98,3.78)$ & 0.000 & Triple-negative & $2.51(1.77,3.56)$ & 0.000 \\
\hline Lung metastases & & & Lung metastases & & \\
\hline No & Reference & & No & Reference & \\
\hline Yes & $1.86(1.49,2.33)$ & 0.000 & Yes & $1.60(1.27,2.03)$ & 0.000 \\
\hline \multicolumn{6}{|l|}{ Brain metastases } \\
\hline No & Reference & & & & \\
\hline Yes & $1.63(0.98,2.69)$ & 0.058 & & & \\
\hline Bone metastases & & & Bone metastases & & \\
\hline No & Reference & & No & Reference & \\
\hline Yes & $1.26(1.01,1.56)$ & 0.037 & Yes & $1.21(0.96,1.52)$ & 0.107 \\
\hline
\end{tabular}

BCLM, breast cancer liver metastases; Cl, confidence interval; ECOG, Eastern Cooperative Oncology Group; HR, hormone receptor; HER2, human epidermal growth factor receptor 2.

PRL-3, a phosphatase promoting cell migration, invasion and liver metastasis, was found to positively express in HER2-positive breast cancers (22). Further studies to clarify the molecular mechanisms of HER2-mediated breast tumor metastasis to liver may provide new targeted agents for any individual patient.

The multivariate logistic regression analysis (Table 3) showed that patients with de novo stage IV breast cancer were more prone to present with liver metastases than recurrent $\mathrm{MBC}$ patients, which was also found in two prospective observational cohort studies conducted in America $(23,24)$. Besides, patients with lung metastases had smaller likelihood of liver metastases at diagnosis. In other words, liver metastases were less likely to happen with lung metastases simultaneously upon initial diagnosis of MBC. This difference of metastatic sites might be due to the molecular and cellular mechanisms underlying organspecific metastases. Breast cancer expression of DAP12, a transmembrane adapter protein, was reported to promote skeletal and liver metastases, but not lung metastases (25). Early detection of biomarkers involving in tissue-specific metastases may be beneficial to clinical determination.
Therefore, more mechanistic studies associated with organ metastases in breast cancer are desirable for clinical practice.

The median OS of BCLM patients was 31.4 months, remarkably poorer than non-BCLM patients, the median OS of whom was 50.0 months. The survival of BCLM patients in our data seemed longer than the reported survival of BCLM patients in former retrospective studies, ranging from 12 to 20 months (7-10). Additionally, we observed that BCLM patients with triple-negative subtype had the shortest survival (18.0 months) compared with other subtypes, consistent with previous publications $(17,26,27)$. In a California cohort of 6,268 de novo $\mathrm{MBC}$ patients, the median survival of TNBC patients was much shorter (12 months) than other subtypes (28). There was no significant difference in outcome among HR+/HER2(38.2 months), HR-/HER2+ (29.0 months) and HR+/HER2+ (31.9 months) subtypes, probably thanks to the dramatically improved anti-HER2 therapies (29).

We also determined independent risk factors for survival of BCLM patients using univariable and multivariable analyses (Table 4). Performance status, age, stage of initial breast cancer 
have been proven to be prognostic parameters in multiple studies (30-32), similar to our results. Additionally, the presence of extrahepatic metastases was demonstrated to worsen outcome in BCLM patients $(33,34)$. In our study, BCLM patients presenting with lung metastases simultaneously had a more unfavorable survival than those without lung metastases. Similar tendency was seen in patients developing brain metastases but the result did not reach significance, which might be due to the rare occurrence of brain metastases at initial MBC diagnosis (35).

Our study had some limitations. Firstly, reassessment of the metastatic tumor receptor status was beneficial since changes in tumor phenotype have been found between primary and recurrent breast cancer (36). Secondly, there was no record of the extension and lesion of liver metastases, which were important prognostic factors for BCLM patients (26). Finally, the retrospective setting of this study required a multicenter, large-scale and prospective research to confirm the results.

In summary, our study offers insights into the incidence and prognosis of BCLM patients at initial MBC diagnosis in Han population. It summarizes the clinicopathological features of BCLM patients stratified by breast cancer subtype and helps to identify MBC patients with high risk of liver metastases. Additionally, it provides essential information on prognostic factors of BCLM patients, which is beneficial to personalized treatment in clinical practice. Further strategies covering early screening and prognosis evaluation for BCLM patients are warranted to optimize the disease outcome.

\section{REFERENCES}

1. Torre LA, Bray F, Siegel RL, Ferlay J, Lortet-Tieulent J, Jemal A. Global Cancer Statistics, 2012. CA Cancer J Clin (2015) 65(2):87-108. doi: 10.3322/ caac. 21262

2. Dawood S, Broglio K, Ensor J, Hortobagyi GN, Giordano SH. Survival Differences Among Women With De Novo Stage IV and Relapsed Breast Cancer. Ann Oncol (2010) 21(11):2169-74. doi: 10.1093/annonc/mdq220

3. Cardoso F, Spence D, Mertz S, Corneliussen-James D, Sabelko K, Gralow J, et al. Global Analysis of Advanced/Metastatic Breast Cancer: Decade Report (2005-2015). Breast (Edinburgh Scotland) (2018) 39:131-8. doi: 10.1016/ j.breast.2018.03.002

4. Kennecke H, Yerushalmi R, Woods R, Cheang MC, Voduc D, Speers CH, et al. Metastatic Behavior of Breast Cancer Subtypes. J Clin Oncol (2010) 28 (20):3271-7. doi: 10.1200/jco.2009.25.9820

5. Tasleem S, Bolger JC, Kelly ME, Boland MR, Bowden D, Sweeney KJ, et al. The Role of Liver Resection in Patients With Metastatic Breast Cancer: A Systematic Review Examining the Survival Impact. Ir J Med Sci (2018) 187 (4):1009-20. doi: 10.1007/s11845-018-1746-9

6. Soni A, Ren Z, Hameed O, Chanda D, Morgan CJ, Siegal GP, et al. Breast Cancer Subtypes Predispose the Site of Distant Metastases. Am J Clin Pathol (2015) 143(4):471-8. doi: 10.1309/ajcpyo5fsv3upexs

7. Largillier R, Ferrero JM, Doyen J, Barriere J, Namer M, Mari V, et al. Prognostic Factors in 1,038 Women With Metastatic Breast Cancer. Ann Oncol (2008) 19(12):2012-9. doi: 10.1093/annonc/mdn424

8. Pentheroudakis G, Fountzilas G, Bafaloukos D, Koutsoukou V, Pectasides D, Skarlos D, et al. Metastatic Breast Cancer With Liver Metastases: A Registry Analysis of Clinicopathologic, Management and Outcome Characteristics of 500 Women. Breast Cancer Res Treat (2006) 97(3):237-44. doi: 10.1007/ s10549-005-9117-4

9. Zhao HY, Gong Y, Ye FG, Ling H, Hu X. Incidence and Prognostic Factors of Patients With Synchronous Liver Metastases Upon Initial Diagnosis of Breast

\section{DATA AVAILABILITY STATEMENT}

The raw data supporting the conclusions of this article will be made available by the authors, without undue reservation.

\section{ETHICS STATEMENT}

Written informed consent was not obtained from the individual(s) for the publication of any potentially identifiable images or data included in this article.

\section{AUTHOR CONTRIBUTIONS}

Conception and design: BX. Assembly of data: All authors. Data analysis and interpretation: SL. Manuscript writing: All authors. All authors contributed to the article and approved the submitted version.

\section{FUNDING}

This work was supported by National Key R\&D Program of China (2018YFC1312101) and Chinese Academic of Medical Sciences Initiative for Innovative Medicine (CAMS-12M-1-010).
Cancer: A Population-Based Study. Cancer Manage Res (2018) 10:5937-50. doi: $10.2147 / \mathrm{cmar} . s 178395$

10. Xie J, Xu Z. A Population-Based Study on Liver Metastases in Women With Newly Diagnosed Breast Cancer. Cancer Epidemiol Biomarkers Prev (2019) 28 (2):283-92. doi: 10.1158/1055-9965.epi-18-0591

11. Molnár IA, Molnár B, Vízkeleti L, Fekete K, Tamás J, Deák P, et al. Breast Carcinoma Subtypes Show Different Patterns of Metastatic Behavior. Virchows Arch (2017) 470(3):275-83. doi: 10.1007/s00428-017-2065-7

12. Sihto H, Lundin J, Lundin M, Lehtimäki T, Ristimäki A, Holli K, et al. Breast Cancer Biological Subtypes and Protein Expression Predict for the Preferential Distant Metastasis Sites: A Nationwide Cohort Study. Breast Cancer Res (2011) 13(5):R87. doi: 10.1186/bcr2944

13. Tampellini M, Berruti A, Gerbino A, Buniva T, Torta M, Gorzegno G, et al. Relationship Between CA 15-3 Serum Levels and Disease Extent in Predicting Overall Survival of Breast Cancer Patients With Newly Diagnosed Metastatic Disease. Br J Cancer (1997) 75(5):698-702. doi: 10.1038/bjc.1997.124

14. Lobbezoo DJ, van Kampen RJ, Voogd AC, Dercksen MW, van den Berkmortel F, Smilde TJ, et al. Prognosis of Metastatic Breast Cancer: Are There Differences Between Patients With De Novo and Recurrent Metastatic Breast Cancer? Br J Cancer (2015) 112(9):1445-51. doi: 10. 1038/bjc.2015.127

15. Malmgren JA, Mayer M, Atwood MK, Kaplan HG. Differential Presentation and Survival of De Novo and Recurrent Metastatic Breast Cancer Over Time: 1990-2010. Breast Cancer Res Treat (2018) 167(2):579-90. doi: 10.1007/ s10549-017-4529-5

16. Smid M, Wang Y, Zhang Y, Sieuwerts AM, Yu J, Klijn JG, et al. Subtypes of Breast Cancer Show Preferential Site of Relapse. Cancer Res (2008) 68 (9):3108-14. doi: 10.1158/0008-5472.can-07-5644

17. Leone BA, Vallejo CT, Romero AO, Machiavelli MR, Pérez JE, Leone J, et al. Prognostic Impact of Metastatic Pattern in Stage IV Breast Cancer At Initial Diagnosis. Breast Cancer Res Treat (2017) 161(3):537-48. doi: 10.1007/s10549016-4066-7 
18. Kaplan MA, Arslan UY, Işıkdogan A, Dane F, Oksuzoglu B, Inanc M, et al. Biological Subtypes and Distant Relapse Pattern in Breast Cancer Patients After Curative Surgery (Study of Anatolian Society of Medical Oncology). Breast Care (Basel Switzerland) (2016) 11(4):248-52. doi: 10.1159/000448186

19. Shen T, Siegal GP, Wei S. Clinicopathologic Factors Associated With De Novo Metastatic Breast Cancer. Pathol Res Pract (2016) 212(12):1167-73. doi: 10.1016/j.prp.2016.09.007

20. Pierobon M, Ramos C, Wong S, Hodge KA, Aldrich J, Byron S, et al. Enrichment of PI3K-AKT-mTOR Pathway Activation in Hepatic Metastases From Breast Cancer. Clin Cancer Res (2017) 23(16):4919-28. doi: 10.1158/1078-0432.ccr-16-2656

21. Li YM, Pan Y, Wei Y, Cheng X, Zhou BP, Tan M, et al. Upregulation of CXCR4 is Essential for HER2-mediated Tumor Metastasis. Cancer Cell (2004) 6(5):459-69. doi: 10.1016/j.ccr.2004.09.027

22. Ustaalioglu BB, Bilici A, Barisik NO, Aliustaoglu M, Vardar FA, Yilmaz BE, et al. Clinical Importance of Phosphatase of Regenerating Liver-3 Expression in Breast Cancer. Clin Transl Oncol (2012) 14(12):911-22. doi: 10.1007/ s12094-012-0880-5

23. Yardley DA, Kaufman PA, Brufsky A, Yood MU, Rugo H, Mayer M, et al. Treatment Patterns and Clinical Outcomes for Patients With De Novo Versus Recurrent HER2-positive Metastatic Breast Cancer. Breast Cancer Res Treat (2014) 145(3):725-34. doi: 10.1007/s10549-014-2916-8

24. Tripathy D, Brufsky A, Cobleigh M, Jahanzeb M, Kaufman PA, Mason G, et al. De Novo Versus Recurrent Her2-Positive Metastatic Breast Cancer: Patient Characteristics, Treatment, and Survival From the SystHERs Registry. Oncologist (2020) 25(2):e214-e22. doi: 10.1634/theoncologist.2019-0446

25. Shabo I, Olsson H, Stål O, Svanvik J. Breast Cancer Expression of DAP12 is Associated With Skeletal and Liver Metastases and Poor Survival. Clin Breast Cancer (2013) 13(5):371-7. doi: 10.1016/j.clbc.2013.05.003

26. Duan XF, Dong NN, Zhang T, Li Q. The Prognostic Analysis of Clinical Breast Cancer Subtypes Among Patients With Liver Metastases From Breast Cancer. Int J Clin Oncol (2013) 18(1):26-32. doi: 10.1007/s10147-011-0336-X

27. Howlader N, Cronin KA, Kurian AW, Andridge R. Differences in Breast Cancer Survival by Molecular Subtypes in the United States. Cancer Epidemiol Biomarkers Prev (2018) 27(6):619-26. doi: 10.1158/1055-9965.epi-17-0627

28. Tao L, Chu L, Wang LI, Moy L, Brammer M, Song C, et al. Occurrence and Outcome of De Novo Metastatic Breast Cancer by Subtype in a Large, Diverse Population. Cancer Causes Control (2016) 27(9):1127-38. doi: 10.1007/ s10552-016-0791-9
29. Wang J, Xu B. Targeted Therapeutic Options and Future Perspectives for HER2-positive Breast Cancer. Signal Transduct Target Ther (2019) 4(1):34. doi: 10.1038/s41392-019-0069-2

30. Puente J, López-Tarruella S, Ruiz A, Lluch A, Pastor M, Alba E, et al. Practical Prognostic Index for Patients With Metastatic Recurrent Breast Cancer: Retrospective Analysis of 2,322 Patients From the GEICAM Spanish El Alamo Register. Breast Cancer Res Treat (2010) 122(2):591-600. doi: 10.1007/ s10549-009-0687-4

31. Clark GM, Sledge GWJr, Osborne CK, McGuire WL. Survival From First Recurrence: Relative Importance of Prognostic Factors in 1,015 Breast Cancer Patients. J Clin Oncol (1987) 5(1):55-61. doi: 10.1200/jco.1987.5.1.55

32. Dafni U, Grimani I, Xyrafas A, Eleftheraki AG, Fountzilas G. Fifteen-Year Trends in Metastatic Breast Cancer Survival in Greece. Breast Cancer Res Treat (2010) 119(3):621-31. doi: 10.1007/s10549-009-0630-8

33. Ji L, Fan L, Zhu X, Gao Y, Wang Z. A Prognostic Model for Breast Cancer With Liver Metastasis. Front Oncol (2020) 10:1342. doi: 10.3389/fonc.2020.01342

34. Abbas H, Erridge S, Sodergren MH, Papoulas M, Nawaz A, Menon K, et al. Breast Cancer Liver Metastases in a UK Tertiary Centre: Outcomes Following Referral to Tumour Board Meeting. Int J Surg (London England) (2017) 44:152-9. doi: 10.1016/j.ijsu.2017.06.049

35. Nam BH, Kim SY, Han HS, Kwon Y, Lee KS, Kim TH, et al. Breast Cancer Subtypes and Survival in Patients With Brain Metastases. Breast Cancer Res (2008) 10(1):R20. doi: 10.1186/bcr1870

36. Dieci MV, Barbieri E, Piacentini F, Ficarra G, Bettelli S, Dominici M, et al. Discordance in Receptor Status Between Primary and Recurrent Breast Cancer has a Prognostic Impact: A Single-Institution Analysis. Ann Oncol (2013) 24(1):101-8. doi: 10.1093/annonc/mds248

Conflict of Interest: The authors declare that the research was conducted in the absence of any commercial or financial relationships that could be construed as a potential conflict of interest.

Copyright (c) 2021 Lin, Mo, Li, Guan, Chen, Wang, Yuan, Wang, Luo, Fan, Cai, Li, Chen, Zhang, Li, Ma and Xu. This is an open-access article distributed under the terms of the Creative Commons Attribution License (CC BY). The use, distribution or reproduction in other forums is permitted, provided the original author(s) and the copyright owner(s) are credited and that the original publication in this journal is cited, in accordance with accepted academic practice. No use, distribution or reproduction is permitted which does not comply with these terms. 